in East Anglian fen areas, such as the fen violet (Viola stagnina Kit.), the heath violet (Viola canina ssp. montana (L.)) and Luzula pallescens (Wahl) Bess, which are found in only one or two other localities in the British Isles. The Fen is equally rich in insect life. The Scolt Head Nature Reserve is one of the classic localities in the British Isles for the study of coastal erosion and sand-and shingle-bank formation and is scarcely less renowned for the variety and richness of its bird and plant life ; it is one of the main terneries on the North Sea coast of Britain and a wintering area for shore larks and other rare birds. Havergate Island has become famous for the postwar establishment of a successful breeding colony of avocets; under protection, the Island has also acquired colonies of Sandwich terns and other interesting species and has become a very valuable feeding and resting station for many types of migrant birds. The agreement provides for the prohibition of shooting so that the Island may also be a sanctuary for wildfowl in the winter, and its invertebrate fauna includes many semi-marine spiders of a species new to science. Apart from the special interest of its bird and invertebrate fauna, the Orford beach shingle is of particular interest in regard to plant colonization.

The Old Winchester Hill Nature Reserve is situated mostly on the Middle Chalk; but its slopes present a great variety of aspects and, besides showing a wide variety of plants, well demonstrate the influence of rabbits on vegetation. Most of the Reserve is rough chalk grassland; but there are patches of well-grown yew and other chalk-loving trees, juniper, hawthorn and of common ling, while a strip of woodland at the bottom of the hill is spreading as ash seedlings invade the grassland.

In Scotland on March 9 the Nature Conservancy officially declared as a new Scottish nature reserve the area known as Tentsmuir Point, Fife. Before it became part of the Kingdom of Fife, Tentsmuir Point is believed to have been part of Southern Pictavia, the capital of which was at Abernethy. Fragments of pottery of the Bronze Age have been found on the Muir, and the pottery remains are both of the prehistoric iron type and the medieval jug type. The earliest settlers were hunters and fishermen who tended to be nomadic and can scarcely have affected its natural biological balance. The destruction of forests, largely to promote sheep-farming, assumed major proportions during the twelfth century, and among its far-reaching effects was to aggravate soil-blow. By about 1780 Tentsmuir was largely tilled, but even then it was the site of extensive lochs or shallow pools which were ultimately drained by ditching. Reclamation of the marshes also disturbed the biological balance, birds such as the bittern and the crane disappearing. Evidence was given to the Royal Commission on Coastal Erosion in 1911 that between $1853-55$ and $1893-95,534$ acres of land were gained from the sea between St. Andrews and the Tay Estuary and 23 acres lost.

The area now declared consists of 92 acres purchased from the Forestry Commission and, besides dunes and intervening slacks reclaimed by natural processes from the sea, the new reserve includes a large extent of foreshore below the present high-water mark. The rapid gaining of ground from the sea affords an excellent site for the study of colonization, first by strand dune plants tolerant of saline conditions, followed by brackish water plants, and finally by the more usual plants of normal light soils. This varied flora includes several rare species and offers great scope for ecological studies, while the insect fauna and bird life are also of unusual interest. The establishment of the reserve fulfils an agreement of the Forestry Commission with the Dundee Naturalists' Society, when the latter relinquished claim to an area of eighty acres within the Tentsmuir Forest which had been set aside as a bird sanctuary. The Forestry Commission-has also agreed not to plant an adjacent elongated dune slack within the Commission boundary and to make this available for study purposes.

\section{THE NATIONAL PHYSICAL LABORATORY, TEDDINGTON REPORT FOR 1952}

HE annual report for 1952 of the National report of the Executive Committee which was presented to the meeting of the general board on May 15 last, together with the more detailed reports, prepared by the respective superintendents, of the work of the various Divisions of the Laboratory.

The Executive Committee states that the main problem during the year under review was how to obtain maximum progress on the more important items of research with an inedequate staff. It is deplored that much effort had to be devoted to work for defence purposes and many short-term investigations undertaken at the cost of the traditional and fundamental tasks of the Laboratory.

Several changes are mentioned, including the transfer of the Radio Division of the Laboratory, first set up in 1933, to the Radio Research Organization and, in view of the close connexion between the work of the High Temperature Mechanical Properties Section and that of the Metallurgy Division in the high-temperature materials field, the incorporation of the Section in the Division until it can be transferred to the Mechanical Engineering Research Laboratory, East Kilbride, probably in five years time. Permission to proceed with the design of the new ship tank and cavitation tunnel to be built at Feltham was obtained, and considerable progress is reported with this work and on the construction of the building for the new High Speed Laboratory on the West Aero site to contain two new high-speed wind tunnels. The room in the aerodynamics building which contained the last remaining 4 -ft. wind tunnel is to be used to house the DEUCE (digital electronic universal computing engine), the engineered version of the pilot model of the ACE (automatic computing engine), and when the new high-speed tunnels come into operation it is intended to convert the large building at present occupied by the duplex tunnel into a much-needed large lecture hall with accommodation for 350 people and into a canteen with adequate facilities for staff and visitors.

The annual open day ${ }^{1}$ was held on May 23, 1952, and was attended by many scientific workers from the universities, government departments and indus. try, and a well-attended conference on the measurement and importance of the elastic properties of metals ${ }^{2}$ took place during March 20-21. On April 22 the Laboratory was honoured by a visit from H.R.H. the Duke of Edinburgh, who spent the morning National Physical Laboratory: Report for the Year 1952. Pp.
viii +72. (London: H.M.S.O., 1953.) 28. 6d. net. 
seeing a representative selection of the Laboratory's work.

The Laboratory again took part in the Physical Society's annual exhibition of scientific instruments and in one of the Royal Society soirées, and also sent exhibits to the International Machine Tool Trades Exhibition at Olympia and to the Fourth Industrial Physics Conference and Exhibition, Glasgow. During the year the proceedings of the 1951 symposium on "Present Developments and 'Techniques in the Maintenance of Standards" was published", and the series of "Test Pamphlets" and the short series on "Units and Standards of Measurement Employed at the Laboratory" were completed. In addition, Nos. 2 and 3 of the series "Notes on Applied Science", entitled "The Industrial Application of Aerodynamic Techniques" and "The Properties of Electrical Insulating Materials and Methods of Test", were issued. The complete list of publications is given in an appendix to the report. The director, Sir Edward Bullard, and many senior members of the staff paid numerous visits to countries overseas to attend conferences, visit laboratories or to obtain supplies of essential materials, and details of these visits are included in the report, together with the names of the members of the general board, executive committee and sub-committees, the positions and names of the senior staff, and bibliographies of the numerous scientific papers published by the director and members of the staff of the Divisions of the Laboratory.

The individus l reports of the various sections of the Laboratory reveal that a wide range of interesting and important investigations have been undertaken. In the Light Division, several applications of the Merton integrating nut to precision linear measurement have been made, including the construction of a machine for producing linear scales of exceptional accuracy by repeated flash projection of the image of a slit upon a photographic plate advanced by the nut. Methods of colorimetry for the evaluation of the colours of fluorescent pigments and inks and 'fluorescent brightness' in detergents have been developed, and work on the properties of thin films has shown how to produce on glass transparent electrically conducting films of very low resistance. Remarkable results were obtained with gold films on a substrate of bismuth oxide. These films are pale straw in colour with a white-light transmission of at least 75 per cent and of electrical resistance as low as 6-7 ohms per 'square'. The Electricity Division has been mainly concerned with precision measurements of the dielectric constants of gases and liquids, and the Electronics Section with the development of digital computing equipment. One of the problems investigated by the Physics Division has been the reduction of noise from jet-engine test houses, and experiments have been made on the effectiveness of absorbent ducts as silencers. Research work and the results of trials conducted by the Ship Division have proved the importance of making hull-surfaces smooth and keeping them smooth, but the work has also shown that, even with the most carefully conducted trials, results fluctuate a great deal. This emphasizes the importance of detailed attention to every feature that can influence the performance of a ship.

In the report of the Metallurgy Division mention is made of the extension to the Division's laboratories to provide additional facilities for X-ray, electron diffraction and electron microscopy examination of metals and for radioactive tracer work. The effect of phosphorus on the embrittlement of iron at low temperatures has been studied, and a procedure established for the preparation of single crystals of iron. The investigation of the creep of metals and alloys has continued, and in collaboration with the Physics Division some very remarkable changes of the elastic properties in samples of chromium near room temperature have been examined.

1 Nature, 170, 527 (1952).

2 Nature, 168, 594 (1951)

${ }^{3}$ Nature, 172, 335 (1953).

\section{CALIFORNIA INSTITUTE OF TECHNOLOGY}

\section{ANNUAL REPORT FOR 1952-53}

HE annual report of the California Institute of Technology for the year ending June 30 , 1953, comprising the reports of the president of the Institute, Dr. L. A. DuBridge, and of the secretary and the comptroller and other administrative officers, together with reports of the different Divisions, are contained in the Bulletin of the Institute (62, No. 4 ; 1953)*. Dr. DuBridge notes that, of graduates accepting employment during the year, 78 per cent went into industry; but 53 per cent of those obtaining the bachelor's degree elected for postgraduate work. The student body is limited to about six hundred, of whom a hundred and eighty are freshmen, and the graduate body is fairly constant at four hundred, the faculty of the Institute numbering 334. Some 550 research papers were published during the year, and among research activities of the period, Dr. DuBridge selects for mention the study by the Seismology Laboratory of the series of earthquakes which were set off by the Arvin earthquake of July 21, 1952. This earthquake was followed by several hundred shocks of lesser magnitude during the year, and more was learned from this series than from all the previous recordings made during the twenty-five years of the Laboratory's existence. Prof. G. W. Housner and his colleagues obtained new data for their studies on earthquake-resistant structures. It was found that the seismic waves could be regarded as produced by a series of pulses, such as would result from a series of discrete slippages of a fault, and this theory will assist the analysis of the effects of strong earth motion on buildings and other structures.

In astronomy, Dr. Walter Baede's discovery that the groups of stars which had previously been used to establish the scale of astronomical distances are of two types, one substantially brighter than the other, indicates that distances had been under-estimated and that the most distant nebulæ visible on plates taken with the 200-in. Hale telescope at Palomar may be as much as two thousand million light-years away instead of one thousand million. New measurements in the Kellogg Laboratory indicate that the various isotopes of hydrogen and helium can account for all the sun's energy and that carbon is not involved at all in the combination of hydrogen into helium.

Geochemical research came into full swing during the year, but the air-conditioning equipment of the

* California Institute of Technology: Annual Reports 1952-53. Comprising the Reports of the President, the Secretary, the 'Comptroller, and Other Administrative Officers. Pp. $v+42$. (Pasadena,
Calif. : California Institute of Technology, 1953.) 